I NTERNAT I ONAL REVIEW

\section{ADVANCING PATIENT'S RIGHTS IN THE NORDIC COUNTRIES}

From: Marja-Leena Perälä PhD, 'International Journal of Nursing Practice' Receiving Editor for the Nordic countries

The issue of patients' rights has received increasing attention at national and international levels in recent years. The topic of patients' rights was under discussion at the recent seminar organised by the World Health Organisation (WHO) with the collaboration of the Nordic Council of Ministers and the Nordic School of Public Health in Copenhagen.

In many countries, it is considered necessary to reinforce basic human rights with a set of specific rights that reflect the particular circumstances of the health-care sector. According to WHO's report ${ }^{1}$ the Nordic countries have been very active in the development of patients' rights legislation; three of these countries (Denmark, Finland and Iceland) have laws on patients' rights in force. In Norway, such legislation is being prepared and in Sweden patients' rights are incorporated in various legislative Acts.

There are several factors driving the move to reinforce patients' rights. Patients are reliant on the health-care system and on health-care professionals and are, therefore, potentially vulnerable; patients need mechanisms to promote and protect their rights. Recent significant developments in medical and information technology may have serious ethical as well as physical implications for human beings. Also, many countries are 'undertaking action to contain costs and to ration health care delivery while holding a general political commitment to maintain and improve equity in health'. ${ }^{1}$

Patients' rights, such as rights to good health care and treatment or to information and self-determination, are also very practical issues which every individual working in a health-care system meets in everyday practice. It is logical to assume that in the future patients' rights in nursing will be an important topic due to the increase in patients' awareness.

\section{REFERENCE}

1 Jliev D, Vienonen M. Patients' Rights Development in Europe. World Health Organization, Regional Office for Europe, 1998.

\section{RESIDENTIAL CARE SERVICES IN HONG KONG}

From: Diana T.F. Lee, 'International Journal of Nursing Practice' Receiving Editor for China

Hong Kong is a small territory situated on the South China coast. As a result of rapid growth in the aged population and changes in family structure, an increasing number of elderly people are seeking residential caring facilities, even when they have family members. Before 1996, the development of the residential care sector took place without any form of regulation. Serious concerns were raised about the quality of care provided in residential care homes, particularly in the mushrooming private aged homes sector. In a territory-wide evaluation of the care provided in these homes, it was found that not only was the skill and appropriateness of nursing care inadequate, but also the quality of care during caring procedures was generally poor. These concerns have resulted in the implementation, in mid 1996, of legislation to control residential care. Residential care homes were given 3 years to improve their services. By mid 1999, all homes were required to have obtained a license for operation. Residential care homes which do not meet the licensing criteria could apply for a central funding scheme to improve their services. However, the licensing criteria were heavily dominated by structural concerns (such as home size, personal space and physical facilities) and the process of care delivery that addresses the competence of the care provider and the interpersonal aspects of the residentprovider relationship was not included in the legislation. Ongoing discussions and debates about promoting the quality of residential care have continued since the enactment of the legislation. By the time this brief report is published, all residential care homes in Hong Kong should have obtained a license for practice. Further research is needed to evaluate whether this legislation has helped to improve the quality of residential care homes. Promoting the quality of residential care will continue to be an important agenda item for Hong Kong. 


\section{HEALTH IN TAIWAN}

From: Ue-Lin Chen, International Journal of Nursing Practice' Receiving Editor for Taiwan

The ten leading causes of death in Taiwan for 1998 have been announced by the National Health Bureau. Cancer remains the number one killer on the island as lung and hepatic cancer have moved onto the cancer list. Health maintenance and promotion related to the lungs and liver will be highly emphasized for research and for public education. All municipal hospitals in Taipei have commenced a long overdue family-centered maternity care policy that encourages the presence of the father during the wife's labor. Conservative and opposition groups have voiced their concerns regarding the policy, for example about its psychological impact on the father. Studies will be undertaken to examine those concerns. The application of the concepts of traditional Chinese medicine in nursing practice has generated tremendous interest among nurse educators and researchers. Issues related to advanced practice in nursing, services provided by nurse midwives and national educational reforms, are all new interests for nurses in Taiwan.

\section{INTERNATIONAL DOCTORAL EDUCATION IN NURSING}

From: Shaké Ketefian RN, EdD, FAAN, 'International Journal of Nursing Practice' Receiving Editor for North and South America

Exponential growth has been noted in doctoral education in recent years in many regions of the world. The impetus for health-care reform, the need for strengthening the overall quality of nursing, the re-emergence of infectious diseases and the AIDS epidemic have highlighted an unprecedented need for nursing leadership. Recognition of the benefits of doctoral preparation toward national and regional development have led to the expansion of these opportunities for nurses.

The rapid expansion of doctoral programs around the world has meant that, in some cases, individuals have had to assume positions of leadership too early in their careers or before nursing science in a given country was sufficiently mature. A clear need has emerged to provide opportunities for peer exchange, dialogue and sharing through collaborative arrangements. In order to meet this need, an international group of nurse educators has initi- ated the establishment of the International Network of Doctoral Education in Nursing (INDEN). This group held its second meeting recently and is now being launched formally. The goal of INDEN is to advance and promote high quality doctoral education through international collaboration and cooperation. Its objectives include: developing quality indicators for doctoral programs; providing opportunities for dialogue and networking among doctoral educators; facilitating exchange of ideas, faculties and students between countries; creating a common vision for the future of doctoral education; and the development of a variety of data bases. Faculty and administrators of doctoral programs, as well as nursing doctoral students, are welcome to join the group. The URL is: http:/ / www.umich.edu/ inden/index.htm

\section{CLINICAL COMPETENCE IN NEW ZEALAND}

From: Professor Alison Dixon, 'International Journal of Nursing Practice’ Receiving Editor for New Zealand

In April this year, the Nursing Council of New Zealand launched its 'Guidelines for Competence Based Practising Certificates for Registered Nurses' ${ }^{1}$ document. Based closely on the United Kingdom model, this document contains one important difference. It applies only to those registered nurses who provide direct nursing care to people in a clinical area or within a nursing service setting. The guidelines further state that while registered nurses who work in education, as researchers, in policy and/or management may influence nursing practice, they are not directly practising nursing. As a consequence of this decision, if these colleagues have not completed 750 hours of actual 'hands on' nursing within a 5-year period they will have to complete a return to practice programme before they can obtain a practising certificate. Regardless of their previous practice experience, such nurses will have to demonstrate that they are able to provide competent nursing care in a clinical area or nursing service setting.

This is an interesting philosophical position for the council to take. What discourses are dominant? One position is that this decision reflects a consensus viewpoint from nursing stakeholder groups that the only real nurses are those who provide direct care. Another position reflects issues of power, because this decision could be seen as an example of oppressed group behaviour. What 
does this position say about a registered nurse's ability to exercise professional judgement and autonomy in their practice? Are these attributes no longer important? Council's rationale for its position is that the public needs assurances that registered nurses have maintained their competence to practice, an unarguable stance. However, the position that colleagues in education, research, policy and management are no longer competent to practice nursing can and will be challenged.

\section{REFERENCE}

1 Nursing Council of New Zealand. Guidelines for Competence Based Practising Certificates for Registered Nurses. Wellington, New Zealand: Nursing Council of New Zealand, 1999. 